\title{
Kegiatan Peer Response pada Kelas Mengarang Bahasa Jepang bagi Pembelajar Bahasa Jepang Tingkat Dasar
}

\author{
Arianty Visiaty \\ Program Studi Sastra Jepang, Fakultas Sastra \\ Universitas Al Azhar Indonesia, Jl. Sisingamangaraja, Jakarta 12110 \\ Penulis untuk korespondensi/E-mail: ariantyvisiaty@uai.ac.id
}

\begin{abstract}
Abstrak - Salah satu kesulitan yang dihadapi pengajar dalam mengajar mengarang bahasa Jepang adalah mengoreksi. Penelitian ini berfokus pada proses ketika kegiatan peer response berlangsung. Hasil dari penelitian ini adalah: 1) topik yang banyak dibicarakan ketika kegiatan peer response berlangsung adalah tentang tata bahasa dan huruf. Sedangkan yang paling sedikit adalah topik tentang isi karangan. 2) Interaksi yang terjadi pada saat kegiatan adalah, saling mempelajari kosakata baru, saling mengevaluasi pengetahuan bahasa, dan saling memberi masukan tentang isi karangan.
\end{abstract}

Abstract - One of the difficulties faced by teachers in teaching Japanese writing is correcting. This study focuses on the process when peer response activities take place. The results of this study are as mentioned below. First, a topic that often arises was about grammar and letters, and the least was the topic of the essay content. Second, the interaction that occured between learners when the activity took place was, learners learned new vocabulary eachother, learners evaluated they knowledge of language each other, and they gived each other feedback on essay content.

Keywords - Peer Response, Peer Learning, Strategy, Indonesian Japanese Learners

\section{PENDAHULUAN}

$\mathrm{S}_{\mathrm{p}}$ alah satu kesulitan yang dihadapi oleh pengajar dalam pengajaran bahasa Jepang khususnya mengarang adalah mengoreksi karangan. Hal ini terjadi khususnya pada kelas dengan jumlah pembelajar banyak. Banyaknya jumlah pembelajar menyulitkan pengajar untuk memberikan feedback hasil karangan secara maksimal kepada masing-masing pembelajar.

Cara yang biasa dilakukan ketika mengoreksi hasil karangan adalah Teacher Feedback. Teacher Feedback adalah kegiatan mengoreksi yang dilakukan oleh pengajar. Pengajar mengoreksi hasil karangan pembelajar, kemudian mengembalikannya kepada pembelajar, untuk ditulis ulang. Akan tetapi karena feedback tidak dilakukan secara langsung oleh pengajar terhadap masing-masing pembelajar, banyak pembelajar tidak paham benar tentang kesalahan yang ada pada karangannya.

Untuk mengatasi hal ini salah satu hal yang dapat dilakukan adalah dengan mengadakan kegiatan peer response. Peer response adalah kegiatan mengoreksi karangan bersama teman. Peer response merupakan bagian dari peer learning.

Dengan dilakukannya peer response dalam pengajaran mengarang, pembelajar dapat memahami kelemahan dan kekurangan dari karangannya, sehingga dapat meningkatkan kemampuan mengarang. Tidak hanya itu kegiatan ini juga dapat menumbuh kembangkan kemampuan bersosialisasi yang akan bermanfaat ketika pembelajar telah lulus dan terjun di masyarakat.

Penelitian mengenai peer response sudah banyak dilakukan, akan tetapi responden dari penelitian tesebut kebanyakan dan pembelajar JSL (Japanese for Second Language: Pembelajar bahasa Jepang yang belajar di Jepang), sedangkan penelitian terhadap pembelajar JFL (Japanese for Foreign Language: Pembelajar bahasa Jepang yang belajar di luar negara Jepang) masih sedikit. Terutama penelitian dengan responden pembelajar asal Asia, lebih jauh lagi dengan responden orang Indonesia. 
Untuk itu perlu dilakukan penelitian mengenai kegiatan peer response di Indonesia dengan responden orang Indonesia, terutama penelitian yang menfokuskan pada proses pembelajaran ketika kegiatan tersebut berlangsung. Dengan mengetahui proses kegiatan peer response diharapkan dapat diketahui apa saja yang perlu dilakukan agar kegiatan peer response dapat berjalan lancar dan efektif dan dapat dijadikan model untuk pengajaran mengarang bahasa Jepang di Indonesia.

\section{LANDASAN TEORI}

Definisi peer response menurut Ikeda adalah, kegiatan mengoreksi hasil karangan yang dilakukan oleh sesama pembelajar dimana pembelajar saling bertukar peran sebagai pembaca dan penulis [1]. Peer response ini dilakukan di dalam grup kecil yang berjumlah antara 2 sampai 4 orang.

Menurut Revers dalam Ikeda [1], kelebihan dari kegiatan peer response adalah sebagai berikut:

1. Meningkatkan keterampilan mengarang. Hal ini dikarenakan penulis sadar akan keberadaan dari pembaca, sehingga tujuan penulisan menjadi jelas, dan mendorong timbulnya daya analisis dan kritisisasi pembelajar.

2. Menumbuhkan kembangkan kemampuan bersosialisasi. Dengan bekerjasama mengoreksi karangan bersama teman, akan terjadi interaksi secara sosial maupun kreatif, dan mendukung pembelajaran yang integratif.

Selain itu Ferris dan Hedgcock dalam Ikeda [2], juga mengungkapkan manfaat dilakukannya peer response, sebagai berikut:

1. Pembelajar bisa mengikuti pelajaran secara aktif.

2. Pembelajar bisa mengevaluasi pendapatnya dengan masukan dari teman.

3. Berdiskusi antara teman atau pengajar dan pembelajar dengan tingkat kegugupan yang rendah dapat menghasilkan sesuatu yang melebihi dari kemampuan.

4. Penulis menerima tanggapan (respon) berupa pertanyaan, pendapat, dll., langsung dari pembacanya.

5. Pembelajar mendapat Feedback dari berbagai sudut pandang.

6. Penulis dapat mengetahui mengenai bagian yang dimengerti dan tidak dimengerti oleh pembaca.
7. Meningkatkan keterampilan mengkritik yang diperlukan untuk mengkoreksi dan menganalisis karangan teman.

8. Meningkatkan rasa saling percaya antara teman dengan saling memahami kelemahan diri sendiri dan kelebihan teman.

Seperti yang telah dijelaskan dalam latar belakang, penelitian yang tentang keefektifan kegiatan peer response sudah banyak dilakukan, diantaranya adalah penelitian Ryuna [3]. Ryuna melakukan penelitian perbandingan antara kegiatan peer response dengan kegiatan teacher feedback. Penelitian ini dilakukan kepada 38 orang mahasiswa pembelajar bahasa Jepang tingkat 3 orang Cina di Cina, dengan menfokuskan pada produk (hasil belajar/nilai) dari kegiatan peer response dan teacher feedback. Hasil penelitiannya adalah, nilai pembelajar yang melakukan kegiatan peer response mengalami peningkatan dibandingkan dengan pembelajar yang hanya mendapat koreksi dari pengajar (teacher feedback). Selain Ryuna, Hirose [4] juga melakukan penelitian tentang keefektifan kegiatan peer respon terhadap mahasiswa tingkat 3 pembelajar bahasa Jepang orang Korea sebanyak 25 orang. Dalam kegiatan peer response yang dilakukan oleh Hirose, bahasa yang dipakai sebagai media percakapan ketika melakukan kegiatan peer response adalah bahasa ibu pembelajar (bahasa Korea), dan kesimpulan dari penelitian ini adalah, koreksi yang dilakukan pembelajar tidak hanya berfokus pada kosakata akan tetapi juga pada isi karangan.

Selain penelitian yang berfokus pada produk (hasil belajar/nilai) seperti yang dilakukan oleh Ryuna di atas, terdapat juga penelitian yang mengacu pada proses. Di antaranya adalah penelitian yang dilakukan oleh Ikeda [1]. Ikeda, melakukan penelitian tentang efektifitas dari peer response pada pembelajar bahasa Jepang tingkat menengah. Penelitian Ikeda merupakan penelitian studi kasus dengan responden terdiri dari satu grup yang beranggotakan dua orang asal Inggris dan Kanada. Dalam penelitian ini Ikeda membandingkan proses yang terjadi pada kegiatan peer response dan teacher-student conferences (koreksi bersama pengajar dan siswa). Hasil dari penelitian ini adalah, 1) pada kegiatan peer response lebih banyak ditemukan interaksi mengenai topik tatabahasa dan kosakata daripada pada kegiatan teacher-student conferences, 2) pada kegiatan peer response ditemukan percakapan yang mempunyai fungsi untuk memacing pendalaman topik 
pembicaraan dan percakapan yang berfungsi untuk mengharmonisasi pembicaraan/ diskusi yang terjadi, sedangkan pada kegiatan teacher-student conferences ciri ini tidak terlihat.

Akan tetapi penelitian-penelitian mengenai peer response di atas, belum dilaksanakan pada pembelajar bahasa Jepang orang Indonesia yang mempunyai latar belakang yang berbeda dengan pembelajar dari negara-negara tersebut di atas, terutama yang belajar bahasa Jepang di Indonesia (JFL). Agar dapat melihat hal-hal apa saja yang diperlukan untuk pengembangan peer response di Indonesia, yang akan menjadi fokus penelitian ini adalah proses pelaksanaan peer response. Untuk tingkat kemampuan dari responden penelitian ini adalah tingkat dasar. Sebagian besar penelitian peer response dilakukan dengan target pembelajar tingkat menengah. Akan tetapi penelitian peer response perlu dilakukan juga pada tingkat dasar untuk melihat kemungkinan dilaksanakannya peer response sejak tingkat dasar, sehingga ketika mamasuki tingkat menengah sudah terbiasa dengan kegiatan peer response. Sedangkan media bahasa yang dipakai dalam percakapan ketika dilaksanakannya peer response adalah bahasa Indonesia. Dari hasil penelitian Ikeda, dikatakan bahwa topik yang sering keluar dalam percakapan peer response adalah mengenai kosakata dan tatabahasa, sedangkan topik mengenai isi karangan hanya sedikit yang keluar dalam percakapan [1]. Hal ini dikarenakan media bahasa yang dipakai dalam diskusi/percakapan adalah bahasa Jepang sehingga pembelajar mengalami kesulitan untuk mengungkapkan pendapat ataupun pikirannya. Sedangkan dalam penelitian Hirose media bahasa yang dipakai dalam percakapan peer response adalah bahasa ibu, dan dari hasil yang penelitian Hirose ini, ditemukan percakapan yang membicarakan tentang isi karangan [4]. Berdasarkan hal tersebut dan juga karena target dalam penelitian ini adalah pembelajar bahasa Jepang tingkat dasar yang kemampuan berbicara bahasa Jepangnya masih rendah, maka dalam penelitian ini akan digunakan bahasa ibu (bahasa Indonesia) sebagai media bahasa yang akan dipakai.

Masih belum adanya penelitian mengenai peer response dengan target pembelajar bahasa Jepang orang Indonesia di Indonesia dan juga untuk mengetahui hal-hal yang diperlukan untuk pengembangan kegiatan peer response di
Indonesia menjadikan penelitian ini penting dilakukan. Penelitian ini akan dilakukan dengan ruang lingkup pembelajar bahasa Jepang orang Indonesia tingkat dasar dan dengan menggunakan bahasa Ibu sebagai bahasa pengantar percakapan dalam kegiatan peer response.

\section{METODE PENELITIAN DAN TEKNIK PENGUMPULAN DATA}

Untuk pengumpulan data dilakukan dengan merekam percakapan ketika dilakukan kegiatan peer response, lalu membuat transkrip rekaman tersebut, sedangkan analisis data dilakukan dengan mengklasifikasi topik berdasarkan penelitian Ikeda mengklasifikasikan interaksi yang terjadi dan kemudian menganalis hasil klasifikasi tersebut [3].

Sumber data dalam penelitian ini adalah pembelajar bahasa Jepang Fakultas Sastra Program Studi Sastra Jepang Universitas Al Azhar Indonesia tingkat 1 semester 2 sebanyak 14 orang.

Penelitian ini memfokuskan pada proses pembelajaran pada kegiatan peer response, dengan permasalahan yang dibahas sebagai berikut:

1. Apa saja yang dijadikan topik pembicaraan ketika kegiatan peer response berlangsung?

2. Interaksi seperti apakah yang terjadi antara pembelajar ketika kegiatan peer response tersebut berlangsung?

Kuliah mengarang tingkat 1 semester 2 Program Studi Jepang UAI dilakukan 1 kali seminggu selama 50 menit. Untuk pengajaran mengarang dengan kegiatan peer response ini dilakukan dalam 8 kali tatap muka. Jadwal selengkapnya pada Tabel 1.

Seperti yang terlihat pada Tabel 1 tema dari mata kuliah mengarang dengan kegiatan peer response, tema karangan terdiri dari dua, yaitu Watashi no Machi (Kota Saya) dan Watashi no Kazoku (Keluarga saya), tema ini diambil dan berdasarkan dari buku "Minna no Nihongo Shokyuu Yasashii Sakubun" terbitan 3 A Corporation. Sedangkan tahapan mata kuliah ini terdiri dari 2 tahap. Tahap satu merupakan tahapan pengenalan dan latihan mengarang dengan kegiatan peer response, sedangkan tahap dua adalah pelaksanaan kegiatan mengarang dengan kegiatan peer response. 
Tabel 1. Jadwal Kuliah Mengarang dengan Semester 2

\begin{tabular}{|c|c|c|c|}
\hline $\mathrm{TM}$ & Tema & Kegiatan & Tahap \\
\hline 1 & $\begin{array}{l}\text { Watashi no } \\
\text { Machi } \\
\text { (Kota } \\
\text { Saya) } 1\end{array}$ & $\begin{array}{l}\text { Pengenalan dan } \\
\text { latihan pola kalimat }\end{array}$ & 司 \\
\hline 2 & $\begin{array}{l}\text { Watashi no } \\
\text { Machi } 2\end{array}$ & $\begin{array}{l}\text { Menulis karangan } \\
\text { ke-1 }\end{array}$ & \\
\hline 3 & $\begin{array}{l}\text { Watashi no } \\
\text { Machi } 3\end{array}$ & $\begin{array}{l}\text { Pengenalan dan } \\
\text { latihan Peer } \\
\text { response }\end{array}$ & \\
\hline 4 & $\begin{array}{l}\text { Watashi no } \\
\text { Machi } 4\end{array}$ & $\begin{array}{l}\text { Kegiatan Peer } \\
\text { Response untuk } \\
\text { karangan ke-1 }\end{array}$ & \\
\hline 5 & $\begin{array}{l}\text { Watashi no } \\
\text { Machi } 5\end{array}$ & Menulis Karangan 2 & \\
\hline 6 & $\begin{array}{l}\text { Watashi no } \\
\text { Kazoku } \\
\text { (Keluarga } \\
\text { Saya) } 1\end{array}$ & $\begin{array}{l}\text { Pengenalan dan } \\
\text { latihan pola kalimat }\end{array}$ & 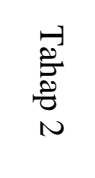 \\
\hline 7 & $\begin{array}{l}\text { Watashi no } \\
\text { Kazoku } 2\end{array}$ & $\begin{array}{l}\text { Menulis karangan } \\
\text { ke-1 }\end{array}$ & \\
\hline 8 & $\begin{array}{l}\text { Watashi no } \\
\text { Kazoku } 3\end{array}$ & $\begin{array}{l}\text { Evaluasi kegiatan } \\
\text { peer response } \\
\text { dengan tema } \\
\text { Watashi no Machi }\end{array}$ & \\
\hline 9 & $\begin{array}{l}\text { Watashi no } \\
\text { Kazoku } 4\end{array}$ & $\begin{array}{l}\text { Kegiatan Peer } \\
\text { Response untuk } \\
\text { karangan ke-1 }\end{array}$ & \\
\hline 10 & $\begin{array}{l}\text { Watashi no } \\
\text { Kazoku } 5\end{array}$ & $\begin{array}{l}\text { Menulis Karangan } \\
\text { ke-2 }\end{array}$ & \\
\hline
\end{tabular}

Adapun urutan dari kegiatan peer response yang dilakukan adalah:

1. Pengenalan tata bahasa yang penting untuk dipakai pada karangan, dan pembuatan kerangka karangan.

2. Untuk karangan dengan tema Watashi no Machi (Kota Saya), pembelajar menulis karangan ke-1 berdasarkan kerangka karangan yang sudah dibuat dan mengumpulkan kepada pengajar. Pengajar tidak memperbaiki karangan ke-1 secara langsung, tapi memberikan simbolsimbol pada bagian yang perlu diperbaiki (misal: _ untuk kesalahan pada huruf, untuk kesalahan pada kosa kata yang digunakan, (2) untuk kalimat yang maknanya tidak bisa dimengerti, dll). Hal ini dilakukan sebagai latihan kegiatan peer response, agar pembelajar bisa mengetahui bagian mana saja yang menjadi point penting untuk diperhatikan ketika mengoreksi sebuah karangan. Sedangkan untuk karangan dengan tema Watashi no Kazoku (Keluarga saya), pembelajar tidak menyerahkan karangan ke-1 ke pengajar.

3. Kegiatan Peer response untuk karangan ke-1

4. Setelah dilakukan kegiatan peer response pada karangan ke-1, pembelajar menulis kembali karangan ke-2 sesuai dengan hasil dari kegiatan peer response.

5. Siswa mengumpulkan karangan ke-2 kepada pengajar untuk dikoreksi oleh pengajar.

\section{HASIL ANALISIS}

\section{Topik Pembicaraan}

Klasifkasi topik pembicaraan yang dilakukan berdasarkan kategori pada penelitian Ikeda [5], yaitu:

1. Tatabahasa : topik tentang tatabahasa

2. Huruf : topik tentang kanji, pelafalan, dll

3. Kosakata : topik tentang arti kosakata

4. Ekspresi : topik tentang cara mengekpresikan suatu hal.

5. Isi : topik tentang situasi, pelaku, struktur keseluruhan, dll.

6. dll : topik yang tidak berkaitan langsung dengan karangan.

Dari data transkrip topik yang keluar pada percakapan dalam kegiatan peer response adalah seperti terlihat pada tabel 2 .

Tebel 2. Jumlah dan Persentase Topik yang Muncul pada Peer Response

\begin{tabular}{clcc}
\hline No. & Kategori & $\begin{array}{c}\text { Jumlah } \\
\text { Topik }\end{array}$ & Persentase \\
\hline 1 & Tatabahasa & 19 & $37.2 \%$ \\
\hline 2 & Huruf & 18 & $35.3 \%$ \\
\hline 3 & Kosakata & 6 & $11.8 \%$ \\
\hline 4 & Ekspresi & 5 & $9.8 \%$ \\
\hline 5 & Isi & 3 & $5.9 \%$ \\
\hline 6 & dll & 0 & $0 \%$ \\
\hline
\end{tabular}

Dari tabel di atas terlihat bahwa topik yang paling banyak keluar adalah topik mengenai tatabahasa (37.2\%), dan topik mengenai huruf (35.3\%), 
dilanjutkan dengan kosakata (11.8\%), ekpresi $(9.8 \%)$ dan topik mengenai isi (5.9\%).

Topik mengenai tatabahasa dan huruf sangat banyak muncul, sedangkan topik mengenai ekspresi dan isi hanya sedikit yang muncul. Hal ini karena karangan yang dibuat bertema sama antara satu dengan lainnya, sederhana, dan berupa pengembangan sederhana dari model karangan yang sudah ada di buku teks, sehingga tidak ada perbedaan isi satu sama lain yang membuat munculnya pertanyaan, kritik, atau komentar tentang isi karangan. Sedangkan untuk sedikitnya jumlah topik ekspresi yang muncul dapat dikarenakan pengetahuan pembelajar tingkat dasar mengenai ekspresi bahasa Jepang masih sedikit. Sehingga topik pengoreksian hanya berfokus pada tatabahasa dan huruf.

Hal tersebut di atas juga terlihat pada penelitian Ikeda (1999)[5], dimana topik mengenai isi adalah topik yang paling sedikit keluar. Salah satu penyebabnya adalah karena tema karangan yang ditulis sama untuk semua pembelajar.

\section{Interaksi pada Kegiatan Peer Response}

Berdasarkan data trankrip yang dapat dikatakan bahwa, interaksi yang terjadi pada saat kegiatan peer response adalah:

1. Saling mempelajari kosakata baru

2. Saling mengevaluasi pengetahuan bahasa (kosakata, huruf, tatabahasa)

3. Saling memberi masukan tentang isi karangan

\section{Saling Mempelajari Kosakata Baru}

Dari data transkrip terlihat bahwa terjadi interaksi saling mempelajari kosakata baru antar pasangan peer response. Contoh dari interaksi ini dapat dilihat pada percakapan tabel 3 .

Tabel 3. Contoh Percakapan 1 (S:Pemeriksa, K:Penulis)

\begin{tabular}{ccl}
\hline No. & $\begin{array}{c}\text { Kode } \\
\text { Nama }\end{array}$ & \multicolumn{1}{c}{ Percakapan } \\
\hline 1 & $\mathrm{~S}$ & $\begin{array}{l}\text { wakai koro (waktu muda) } \\
\text { tuh, apa tuh wakai koro }\end{array}$ \\
\hline 2 & $\mathrm{~K}$ & $\begin{array}{l}\text { wakai koro tu, waktu, waktu } \\
\text { muda gitu }\end{array}$ \\
\hline
\end{tabular}

Pada percakapan 1 di atas, $\mathrm{S}$ membaca karangan $\mathrm{K}$, dan menemukan kosakata yang belum dipelajari, yaitu wakaikoro (waktu muda).
Kemudian, $\mathrm{S}$ bertanya kepada $\mathrm{K}$ tentang arti dari kata tersebut (1S) dan K menjawab bahwa arti dari wakaikoro adalah "waktu muda". Contoh lainnya, adalah seperti pada tabel 4 .

Tabel 4. Contoh Percakapan 2 (K:Pemeriksa, S:Penulis)

\begin{tabular}{ccl}
\hline No. & $\begin{array}{c}\text { Kode } \\
\text { Nama }\end{array}$ & \multicolumn{1}{c}{ Percakapan } \\
\hline 1 & $\mathrm{~K}$ & $\begin{array}{l}\text { S tidak ada yang salah sepertinya } \\
\text { hehehe(baca) kenchiki no koumon } \\
\text { (konsultan desain) itu apa? }\end{array}$ \\
\hline 2 & S $\quad \begin{array}{l}\text { kenchiku no koumon itu, waktu itu } \\
\text { aku nyarinya perkata sih itu, } \\
\text { pokoknya artinya konsultan arsitek } \\
\text { gitu deh. }\end{array}$ \\
\hline
\end{tabular}

Pada percakapan 2, K tidak mengerti kata kenchiku no koumon (konsultan desain) dalam karangan $\mathrm{S}$ sehingga bertanya maknanya kepada $\mathrm{S}$. Dengan bertanya maka $\mathrm{S}$ mendapat pengetahuan baru tentang kosa kata.

Pada data transkrip penelitian ini hanya ditemukan interaksi saling mempelajari kosakata baru. Penyebab yang pertama adalah karena tema yang sangat sederhana dan tidak memerlukan kalimat yang kompleks, sehingga pembelajar tidak tertantang untuk membuat karangan dengan menggunakan tatabahasa, kanji, ataupun ekspresi yang baru. Penyebab yang ke dua adalah responden dari penelitian ini adalah responden dengan kemampuan bahasa Jepang tingkat dasar, sehingga masih susah untuk mengembangkan tatabahasa ataupun ekpresi yang dipakai dalam sebuah karangan.

\section{Saling Mengevaluasi Pengetahuan Bahasa diri sendiri (kosakata, huruf, tatabahasa)}

Selain saling mempelajari kosakata baru, terlihat interaksi saling mengevaluasi pengetahuan bahasa seperti pengetahuan kosakata, huruf, tatabahasa, dan ekspresi. Dengan kegiatan peer response, maka penulis karangan dapat mengetahui letak kesalahannya dimana dan dapat memperbaiki kesalahan tersebut. Apabila pengoreksian dilakukan dengan teacher feedback, ada kemungkinan pembelajar tidak membaca kembali hasil koreksian dari pegajar. Dengan melakukan peer response, pembelajar dapat menyadari betul letak kesalahannya dimana, karena dikoreksi secara langsung, dan tidak akan melakukan kesalahan yang sama di masa yang akan datang. 
Contoh evaluasi pengetahuan kosakata bisa dilihat dalam percakapan tabel 5 .

Tabel 5. Contoh Percakapan 3 (J:Pemeriksa, I:Penulis)

\begin{tabular}{|c|c|c|}
\hline No. & $\begin{array}{l}\text { Kode } \\
\text { Nama }\end{array}$ & Percakapan \\
\hline 1 & $\mathrm{D}$ & $\begin{array}{l}\text { ehm trus ini yang (baca), ini } \\
\text { kayaknya lebih enak kalau } \\
\text { misalnya coboy juniaa (junior) } \\
\text { gitu }\end{array}$ \\
\hline 2 & $\mathrm{C}$ & oh jadi bukan junioru? \\
\hline 3 & $\mathrm{D}$ & junioru \\
\hline 4 & $\mathrm{C}$ & $\begin{array}{lll}\text { jadi coboy juniaa } & \text { gitu, } \\
\text { panjang? } & & \\
\end{array}$ \\
\hline 5 & $\mathrm{D}$ & iya kayaknya sih lebih enak itu \\
\hline 6 & $\mathrm{C}$ & ehm \\
\hline
\end{tabular}

Tabel 6. Contoh Percakapan 4 (J:Pemeriksa, I:Penulis)

\begin{tabular}{|c|c|c|}
\hline No. & $\begin{array}{l}\text { Kode } \\
\text { Nama }\end{array}$ & Percakapan \\
\hline 1 & $\mathrm{~J}$ & $\begin{array}{l}\text { I disini nulis ehm (baca), } \\
\text { kankoku (Korea) nya ditulis } \\
\text { pake katakana trus dorama } \\
\text { (Drama)nya ditulis pake } \\
\text { hiragana. }\end{array}$ \\
\hline 2 & $\mathrm{I}$ & hem \\
\hline 3 & $\mathrm{~J}$ & $\begin{array}{l}\text { aturan ehm kankokunya itu } \\
\text { ditulis pake hiragana }\end{array}$ \\
\hline 4 & I & hiragana \\
\hline 5 & $\mathrm{~J}$ & $\begin{array}{l}\text { pake hiragana aja he eh, atau } \\
\text { gak pake kanji }\end{array}$ \\
\hline 6 & $\mathrm{I}$ & oh berarti terbalik ya hehe \\
\hline 7 & $\mathrm{~J}$ & $\begin{array}{l}\text { iya terbalik doramanya justru } \\
\text { pake hiragana kan }\end{array}$ \\
\hline 8 & I & ehm iya ya \\
\hline 9 & $\mathrm{~J}$ & seharusnya katakana \\
\hline 10 & $\mathrm{I}$ & he eh ya iya \\
\hline 11 & $\mathrm{~J}$ & $\begin{array}{l}\text { itu dua kali ditulis, disini juga } \\
\text { sama (baca) }\end{array}$ \\
\hline 12 & I & he ehm \\
\hline
\end{tabular}

Pada percakapan 3D menkritik kosakata yang digunakan oleh $\mathrm{C}$ di dalam karangan. $\mathrm{C}$ menggunakan kosakata Junioru (Junior), D menyarankan $\mathrm{C}$ untuk mengubahnya menjadi
Juniaa (Junior) (3D), dan C bisa menerima masukan dan memahami kesalahannya dan memperbaikinya dalam karangan ke-2. Evaluasi pengetahuan huruf bisa terlihat pada contoh percakapan tabel 6 .

Pada contoh percakapan $4, \mathrm{~J}$ (pemeriksa) melihat kesalahan penulisan huruf pada karangan I (Penulis). I menulis kata kankoku (Korea) yang seharusnya ditulis dengan hiragana atau kanji dengan huruf katakana, sementara kata dorama (drama) yang seharusnya ditulis dengan menggunakan katakana, ditulis dengan menggunakan huruf hiragana. J mengkritik bahwa terjadi kesalahan penulisan huruf (1J). Dengan penjelasan dari J, I bisa menyadari kesalahan pemakaian huruf yang terbalik antara hiragana dan katakana. Hal ini terlihat pada percakapan 6I "oh berarti terbaliknya hehe". Untuk contoh evaluasi terhadap tatabahasa adalah seperti contoh tabel 7 .

Tabel 7. Contoh Percakapan 5 (S:Pemeriksa, T:Penulis)

\begin{tabular}{lll}
\hline No. & $\begin{array}{c}\text { Kode } \\
\text { Nama }\end{array}$ & \multicolumn{1}{c}{ Percakapan } \\
\hline he eh, biar jelas. Trus sama \\
yang kakak perempuan juga \\
gitu,kalau bisa pake shumi wa \\
sh ( Hobi) ehm .. wo kitari \\
(mendengar), sama yang punya \\
T juga shumi wa shashin wo \\
torit...(hobinya mengambil \\
foto)
\end{tabular}

Pada percakapan $5 \mathrm{~S}$ mengkritik adanya kesalahan konjugasi pada kata kerja. Katakerja toru (mengambil) yang seharusnya menjadi tottari apabila berkonjugasi menjadi bentuk ta, tertulis toritari pada karangan Y. Pada pernyataan 1S, S merasakan adanya kesalahan pada konjugasi kata toru (mengambil) pada karangan $\mathrm{T}$, sehingga 
kegiatan membaca karangan yang sedang dilakukan terhenti "shumi wa shashin wo torit..."(1S). Menyadari hal tersebut $\mathrm{T}$ merasa ragu dengan konjugasi yang ditulis dan memastikan apakah konjugasi yang tulisnya benar atau tidak dengan bertanya "toritari?" (2T). Kemudian $S$ menjawab dengan menyebut konjugasi yang benar "tottari" (3S). Mendengar jawaban S, T menyadari letak kesalahannya "hem, aish ni salah nih, shashin wo tottari" (4T). Pada 5S, S menegaskan kembali bahwa konjugasi yang harus dipakai adalah bentuk $t a$, dan pada $7 \mathrm{~S}$ dan 9S, S menyetujui pendapat T.

Pada penelitian ini, banyak sekali interaksi saling mengevaluasi pengetahuan bahasa. Hal ini terkait dengan kegiatan yang dilakukan yaitu mengoreksi karangan, hanya saja yang membedakan dengan kegiatan teacher feedback adalah pada kegiatan ini pembelajar dapat benar-benar menyadari dan memahami kesalahannya, dikarenakan karangannya dikoreksi secara langsung. Hal ini akan sangat berpengaruh pada penggunaan pengetahuan bahasa tersebut di masa yang akan datang. Dengan menyadari sendiri kesalahan secara rileks maka diharapkan kesalahan yang sama tidak akan terulang lagi di masa yang akan datang.

\section{Saling Memberi Masukan tentang Isi Karangan}

Dari data transkrip, terlihat juga interaksi memberi masukan tentang isi karangan seperti pada contoh percakapan tabel 8 .

Pada contoh percakapan 7, M memberi masukan kepada L mengenai isi paragraph terakhir. Pada paragraph terakhir karangannya $\mathrm{L}$ tidak menulis kesimpulan tentang keluarganya, sehingga karangannya menggantung. $\mathrm{M}$ pada $11 \mathrm{M}$, memberi masukan bahwa sebaiknya L memberi kesimpulan tentang keadaan keluarganya dengan menulis mengenai kegiatan yang rutin dilakukan oleh keluarga L. Pada 2 L terlihat bahwa L menerima masukan dari M "baiklah kalau begitu".

Pada data yang ada, terlihat juga interaksi yang berupa saling memberi masukan tentang isi karangan, akan tetapi seperti pada topik, jumlah interaksi ini sangat sedikit. Hal ini dikarenakan tema yang sederhana dan sempit, serta pemilihan tema yang sama untuk semua pembelajar.
Tabel 8. Contoh percakapan 7 (M:pemeriksa, L:penulis)

\begin{tabular}{|c|c|c|}
\hline No. & $\begin{array}{c}\text { Kode } \\
\text { Nama }\end{array}$ & Percakapan \\
\hline 1 & M & $\begin{array}{l}\text { ehm terus ehm ada ini nih jangan } \\
\text { lupa kanji suki (suka)nya, di } \\
\text { belakang kanji suki ( suka)ada ki } \\
\text { nya lagi. Ini bacanya satu deh. } \\
\text { Kayaknya kamu harus diperiksa } \\
\text { lagi L-chan. Terus juga, disini } \\
\text { kamu gak nulis ehm } \\
\text { kesimpulannya itu sebenarnya } \\
\text { ehm apa yang menarik dari } \\
\text { keluarga kamu, tapi sedangkan } \\
\text { disini kamu tulis kesimpulannya } \\
\text { itu, kamu sam, kamu tinggal sama } \\
\text { ayah ibu kamu, sama kakak kamu, } \\
\text { kayaknya harusnya kan } \\
\text { kesimpulan keluarga kamu tuh } \\
\text { kegiatan rutinnya tuh apa } \\
\text { misalnya. ehm kayaknya ini harus } \\
\text { diperbaiki lagi deh L-chan, yang } \\
\text { ini,yang paragraf paling terakhir. } \\
\text { kayaknya sih gitu aja. }\end{array}$ \\
\hline 2 & $\mathrm{~L}$ & baiklah kalau begitu \\
\hline 3 & $\mathbf{M}$ & oke \\
\hline
\end{tabular}

\section{KESIMPULAN DAN SARAN}

\section{Kesimpulan Analisis Data Kegiatan Peer Response}

Hasil dari penelitian kegiatan peer response yang diadakan pada pembelajar tingkat dasar Universitas Al Azhar Indonesia adalah sebagai berikut:

1. Topik yang banyak dibicarakan pada kegiatan peer response untuk pembelajar dengan kemampuan bahasa Jepang level dasar adalah topik mengenai tata bahasa dan huruf. Sedangkan yang sedikit dibicarakan adalah topik mengenai isi karangan.

2. Interaksi yang terjadi antara sesama pembelajar terdiri dari tiga, yaitu:

1) Saling mempelajari kosakata baru

2) Saling mengevaluasi pengetahuan bahasa (kosakata, huruf, tatabahasa)

3) Saling memberi masukan tentang isi karangan 
Interaksi saling mempelajari pengetahuan bahasa baru, hanya ditemukan pada kosa kata saja. Tidak ditemukan interaksi saling mempelajari tatabahasa baru, ekpresi baru, dll. Yang paling banyak ditemukan adalah interaksi saling mengevaluasi pengetahuan bahasa, hal ini terkait dengan kegiatan yang dilakukan, yaitu saling mengkoreksi. Sedangkan interaksi saling memberi masukan tentang isi sangat sedikit ditemukan.

Dari hal di atas dapat disimpulkan, kegiatan peer response pada tingkat dasar efektif untuk mengoreksi tatabahasa, huruf, dan kosakata, sedangkan untuk pengembangan isi karangan belum efektif, hal ini dikarenakan, tema-tema karangan yang dapat juga sangat terbatas, sehingga sulit untuk memberikan masukan tentang isi karangan.

Di lihat dari interaksi yang terjadi untuk pengembangan pengetahuan bahasa hanya berfokus pada kosa kata saja, hal ini dikarenakan tema-tema pada tingkat dasar yang sangat sederhana dan tidak memerlukan kalimat yang kompleks, sehingga pembelajar tidak tertantang untuk membuat karangan dengan menggunakan tatabahasa, kanji, ataupun ekspresi yang baru, dan juga karena kemampuan pembelajar yang masih pada tahap dasar, sehingga masih susah untuk mengembangkan tatabahasa ataupun ekspresi yang dipakai. Akan tetapi dengan adanya interaksi saling mengevaluasi satu sama lain secara langsung, maka pembelajar menyadari benar letak kesalahannya, dan sehingga akan lebih masuk ke dalam ingatan. Dengan kegiatan mengoreksi dan dikoreksi ini, diharapkan ke depan pembelajar dapat belajar mandiri dengan memgevaluasi karangannya sendiri.

\section{Saran untuk Pengajaran Mengarang Bahasa Jepang}

Kegiatan peer response dapat dikembangkan untuk pembelajaran mengarang bahasa Jepang tingkat dasar di Indonesia. Akan tetapi diperlukan latihan bertahap mengenai cara mengoreksi atau point-point pengkoreksian, dan juga cara berdiskusi agar pembelajar dapat benar-benar saling berinteraksi dua arah antara satu dengan lainnya.

\section{DAFTAR PUSTAKA}

[1] 池田玲子「日本語作文推敲におけるピア・レ スポンスの効果中級学習者の場合」『言語文 化と日本語教育 17,36-47, 1999 .

[2] 池田玲子・舘岡洋子『ピアラーニング入門 創造的な学びのデザインのため』ひつじ書房, 2007.

[3] 劉娜「中国の日本語作文教育におけるピアレ スポンスの可能性」『際学院教育改革支援プ ログラム「日本文化研究の国際的情報伝達ス キルの育成 活動報告書、平成 19 年度 海外研 修業編』148-150, 2007.

[4] 広瀬和桂子「母語によるピア・レスポンス （peer response）が推敲作文におよばす効果： 韓国人中級学習者を対象とした 3 ヶ月間の授 業活動をとおして」『言語文化と日本語教育』 19, 24-37, 2000.

[5] 池田玲子「ピア・レスポンセが可能にするこ と一中級学習者の場合」『世界日本語教育』9, 29-43, 1999. 